\title{
EFFICACY OF LATERAL WEDGING IN FOOTWEAR IN MEDIAL COIMPARTMENT OSTEOARTHRITIS KNEE
}

KEY WORDS: Osteoarthritis $(\mathrm{OA})$

\section{Suman Badhal*}

\section{U. Singh}

\section{S. L Yadav}

\section{Gita Handa}

(Associate Professor Pmr Safdarjung Hospital New Delhi)ex Post Graduate, Department Of Physical Medicine And Rehabilitation AIIMS New Delhi *Corresponding Author

Professor And Head Department Of Physical Medicine And Rehabilitation AIIMS New Delhi

Professor Department Of Physical Medicine And Rehabilitation AIIMS New Delhi

Professor Department Of Physical Medicine And Rehabilitation AIIMS New Delhi

INTRODUCTION: In Knee osteoarthritis (OA) Shoe modifications, such as lateral-wedge insoles or shock absorbing shoes with insoles, have been recommended for conservative therapy of mild knee OA but with little objective data on Indian patients.

OBJECTIVE : this prospective study was done to study the effect of lateral heel sole wedging (insole) in the patients of $\mathrm{OA}$ of knee (medial compartment) and its relation to function, pain and stiffness parameters status on VAS and WOMAC scale and to see the requirement of the number of Aceclofenac tablets.

METHODS: 60 patients fulfilling the inclusion criteria were enrolled and divided into intervention group $A(30)$ and nonintervention Group B (30) with random allocation. Paired t-test, Wilcoxon sign rank test and Man Whitney U test were applied at significant $\mathrm{p}$-value of $<0.05 \%$.

RESULTS: the reduction of mean difference in pain on VAS and WOMAC scale, improvement in Mean difference in function parameters the mean reduction of pain in standing/ walking, bending and ascending/descending at WOMAC scale was significantly higher in intervention group. Also the mean reduction in the need for aceclofenac was significantly lower in intervention group evident from fourth week onward to fifth and sixth week.

CONCLUSION: The lateral wedging in shoes in medial joint osteoarthritis is beneficial and it can be cost-effective conservative treatment modalities in early osteoarthritis patients, particularly in developing countries as it can reduces the requirement of NSAIDS and improve functional level of patients by reducing pain in various activities.

\section{INTRODUCTION:}

Knee osteoarthritis $(\mathrm{OA})$ is a disease common in older adults. Current treatment is aimed at minimizing pain, maintaining or improving joint mobility, and decreasing functional impairment. In the pathogenesis of knee OA, biomechanical stresses that affect the articular cartilage and subchondral bone have been implicated as important inciting factors $(1,2$, 3 ). During the midstance phase of gait, about 60 to 80 percent of the load is distributed through the medial compartment of the normal knee (4) which is one of the reasons knee $O A$ frequently involves the medial compartment. Varus angulation deformity may occur in medial compartment knee $\mathrm{OA} \&$ contributes to the progression of $\mathrm{OA}$ (5).

An alternate nonoperative approach has been to realign the weight-bearing load through footwear modification. Shoe modifications, such as lateral-wedge insoles or shock absorbing shoes with insoles, have been recommended for conservative therapy of mild knee $\mathrm{OA}(6,7)$.

Material and methods: A Prospective comparative follow up [cross-sectional] study done in PMR department AIIMS Delhi with follow- up at six weeks to study the effect of lateral heel Sole wedging of $1 / 4$ inch height \& rubber (insole) in the patients of $\mathrm{OA}$ knee and its relation to Function, pain and stiffness Parameters status on VAS after 20 meters walk scale of 0 to 10 and WOMAC scale and to see the requirement of the number of Aceclofenac tablets required by patients in insole group Consecutive Patients of either sex, of age between 35 to 75 years suffering from knee $O A$ fulfilling the American college of Rheumatology criteria of classification of osteoarthritis, (8) having grade I, II and III on Kellgren \& Lawrence (9) grading system of patients involving the medial compartment of knee.

Bilateral Knees were taken after taking Informed consent from patient and ethical clearance. The patients with congenital abnormality, deformity or having any systemic diseases, involvement of other compartments like lateral/ pat ell of emoral compartment is ruled out also patients of grade $4 \mathrm{OA}$ knee and those having contrain dication to aceclofenac are ruled out. This study is done in AIIMS New Delhi PMR department from January 2008 to November 2009

The participating patients were divided in two groups: group $A$ and group B (30) in each group by randomly allocating to the two groups. Group $A$ is intervention arm patients in this group were given lateral heel and sole wedging (insole). A 1/4inch wedge of rubber material insert was given on the lateral side of insole of shoes in footwear. Along with this they were be given aceclofenac $100 \mathrm{mg}$ twice daily for 1 week then to continue aceclofenac \& hot fomentation on as required basis and no other pain killer oral and topical were be used. In the group B The patients were be given aceclofenac $100 \mathrm{mg}$ twice daily for a week then were to continue tab. Aceclofenac \& hot fomentation on as required basis and no other pain killer oral and topical were be used along with strengthening exercise is given in both groups. The baseline assessment was done with WOMAC, a valid and disease specific questionnaire that separately defines severity of pain [5 grades], stiffness [2 grades] and knee function [17 grades] experienced during the 24 hours before assessment. The VAS version of the WOMAC was used. Information about analgesic use during the 24 hours before the assessment was also collected. All The mean reduction in the

\begin{tabular}{c|c|c|}
\hline Submitted : $3^{\text {rd }}$ August,2019 & Accepted : $28^{\text {th }}$ September,2019 & Publication : 15 ${ }^{\text {th }}$ November, 2019 \\
\hline www.worldwidejournals.com $\mid$ & &
\end{tabular}


items are rated on a numerical rating scale of 0 (no symptoms/disability) to 10 (maximal symptoms/ disability).The un weighted arithmetic mean of at least $4 / 5$ pain, $1 / 2$ joint stiffness, and 14/17 disability items make up the WOMAC scales, where by 0 again represents the best and 10 the worst health condition. In, the patients of osteoarthritis of medial compartment of knee and follow up was done after a period of six weeks duration. Assessments performed at the end of 6 weeks included adverse events, frequency of aceclofenac use frequency use of the insert, and the WOMAC $^{44-45}$ scale.

Results:Total sixty cases in both groups were enrolled but out of sixty, six cases dropped out. Among the 54 cases consisting of 21 male and 33 females, the mean age was 50.07 years and mean duration of symptoms was 41.57 months. 30 cases
$(55.6 \%)$ were of grade I osteoarthritis and 18 (33.3\%) with grade II osteoarthritis and $6(11.1 \%)$ with grade III osteoarthritis. Both the groups are comparable in age, sex and duration of symptoms The patients in group $A$ wore lateral wedge with mean duration of $7.38 \pm 1.038$ hours standard deviation, ranging from minimum of five hours to maximum of ten hours. Compliance to lateral wedge wearing was good and in our study none of the patient reported any adverse effect or discomfort with lateral wedge insole the reduction of mean difference for pain on VAS and WOMAC scale along with pain subcomponents viz., pain while walking on flat surface, pain while going upstairs and pain in bed at 6 weeks from baseline in group $A$ was significantly higher than group $B$. The mean difference reduction for subcomponent pain in sitting/lying and pain on standing upright was not significant. As shown in table 1

\begin{tabular}{|c|c|c|c|c|c|c|c|}
\hline \multicolumn{8}{|c|}{ Table 1 Pain parameters } \\
\hline Parameter & Group A mea & nts.d & Group B mean & \pm s.d & Mean differencegroup $A$ & Mean difference group B & Pvalue \\
\hline & 0 week & 6 week & 0 week & 6 week & & & \\
\hline Pain onVAS & $4.34 \pm 1.98$ & $2.76 \pm 1.921$ & $4.04 \pm 2.26$ & $3.08 \pm 2.43$ & 1.586 & .96 & $<.002$ \\
\hline $\begin{array}{l}\text { Pain on } \\
\text { WOMAC }\end{array}$ & $2.769 \pm 1.162$ & $1.76 \pm .872$ & $2.541 \pm 1.038$ & $1.90 \pm .95$ & 1.008 & .639 & $<.004$ \\
\hline
\end{tabular}

Though mean difference reduction in stiffness at 6 weeks from baseline in lateral wedging group was higher than lateral wedging group but it was not statistically significant.

The reduction in mean difference in function parameters at 6 weeks from baseline in group A was significantly higher than group $B$. The mean reduction was also significantly more in group A as compared to group B for subcomponents viz. bending to floor, walking on flat, rising from sitting, getting in/out of car, going shopping and rising from bed. Though it was also more in group A than B for other subcomponents of function viz. descending stairs, ascending stairs, putting on socks and taking off socks but was not significant statistically.

\section{WOMAC FUNCTION PARAMETERS TABLE 2}

\begin{tabular}{|c|c|c|c|c|c|c|c|}
\hline \multirow[t]{3}{*}{$\begin{array}{l}\text { Parameter } \\
\text { mean } \pm \text { S.D }\end{array}$} & \multirow{2}{*}{\multicolumn{2}{|c|}{\begin{tabular}{|l|} 
Group A \\
Time of assessment \\
\end{tabular}}} & \multirow{2}{*}{\multicolumn{2}{|c|}{\begin{tabular}{|l|} 
GROUP B \\
Time of assessment
\end{tabular}}} & \multicolumn{2}{|c|}{$\begin{array}{l}\text { intragroup Mean } \\
\text { difference b/w 0-6 weeks }\end{array}$} & \multirow{3}{*}{\begin{tabular}{|l|}
$\begin{array}{l}\text { Significance level } \\
\text { betwaeen groups }\end{array}$ \\
p-value at 6-week \\
\end{tabular}} \\
\hline & & & & & \multirow[t]{2}{*}{ Group A } & \multirow[t]{2}{*}{ Group B } & \\
\hline & 0-week & 6-week & 0-week & 6 week & & & \\
\hline descending stairs & $4.24 \pm 1.35$ & $3 \pm 1.25$ & $3.72 \pm 2.03$ & $2.84 \pm 1.97$ & 1.21 & .88 & .005 \\
\hline ascending stairs & $5.55 \pm 1.66$ & $4.14 \pm 1.48$ & $5.24 \pm 1.39$ & $4.0 \pm 1.56$ & 1.41 & 1.2 & .289 \\
\hline Rising from sitting & $2.93 \pm 1.64$ & $1.86 \pm 1.32$ & $2.52 \pm 1.58$ & $1.68 \pm 1.46$ & 1.06 & .84 & .148 \\
\hline standing & $2.38 \pm 1.63$ & $1.45 \pm 1.57$ & $1.88 \pm 1.33$ & $1.24 \pm 1.16$ & .93 & .64 & .096 \\
\hline bending to floor & $1.24 \pm 1.12$ & $.55 \pm .87$ & $1.04 \pm 1.39$ & $.72 \pm 1.17$ & .68 & .32 & .045 \\
\hline walking on flat & $3.38 \pm 1.42$ & $2.21 \pm 1.37$ & $2.68 \pm 1.70$ & $1.88 \pm 1.50$ & 1.17 & .80 & .021 \\
\hline getting in/out of car & $3.79 \pm 1.97$ & $2.45 \pm 1.84$ & $3.28 \pm 1.96$ & $2.48 \pm 1.75$ & 1.34 & .80 & .003 \\
\hline going shopping & $3.24 \pm 1.84$ & $2.24 \pm 1.50$ & $2.76 \pm 1.94$ & $2.12 \pm 1.76$ & 1.0 & .64 & .037 \\
\hline putting on socks & $.31 \pm .604$ & $.1 \pm .31$ & $.48 \pm 1.87$ & $.4 \pm 1.63$ & .20 & .08 & .304 \\
\hline rising from bed & $1.86 \pm 1.32$ & $1.03 \pm 1.14$ & $1.72 \pm 1.86$ & $1.12 \pm 1.64$ & .82 & .60 & .035 \\
\hline taking off socks & $.21 \pm .77$ & $.1 \pm .55$ & $.4 \pm 1.80$ & $.32 \pm 1.6$ & .10 & .08 & .769 \\
\hline lying in bed & $2.28 \pm 2.29$ & $1.55 \pm 1.82$ & $2.12 \pm 2.31$ & $1.6 \pm 2.14$ & .72 & .52 & .255 \\
\hline getting in/out of bath & $2.79 \pm 2.22$ & $1.79 \pm 1.74$ & $2.44 \pm 2.31$ & $1.76 \pm 1.80$ & 1.0 & .68 & .179 \\
\hline sitting & $3 \pm 2.29$ & $1.93 \pm 1.99$ & $2.68 \pm 2.28$ & $1.96 \pm 1.90$ & 1.069 & .72 & .058 \\
\hline getting on/off toilet & $3.41 \pm 1.88$ & $2.41 \pm 1.47$ & $3.24 \pm 1.56$ & $2.24 \pm 1.33$ & 1.0 & 1.0 & .436 \\
\hline \multirow[t]{2}{*}{ Heavy domestic duties } & $1.59 \pm 1.72$ & $.90 \pm 1.44$ & $1.36 \pm 1.65$ & $.8 \pm 1.47$ & .68 & .56 & .550 \\
\hline & $.31 \pm .541$ & $.14 \pm .351$ & $.48 \pm 1.04$ & $.24 \pm .83$ & .17 & .24 & .542 \\
\hline
\end{tabular}

need for aceclofenac was significantly lower in group $A$ as compared to group B from fourth week onward to fifth and sixth week, though mean tablets required in group $A$ was less than group B, it was not significant statistically.

\section{Chart 1}

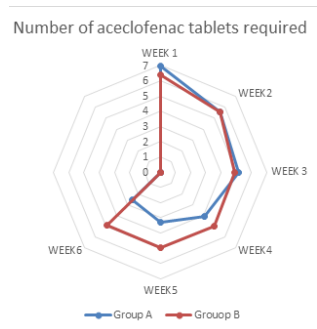

\section{DISCUSSION:}

The reduction in mean difference at 6 weeks from baseline in lateral wedging group was significantly higher than nonintervention group for pain score on VAS \& WOMAC scale along with pain subcomponents viz., pain while walking on flat surface, pain while going upstairs and pain in bed.

The mean difference reduction for subcomponent pain in sitting/lying and pain on standing upright was not significant. The reduction in pain is most likely due to decrease in adduction moment. It seems that wedges increase the valgus moment arm at the subtalar joint, causing a lateral shift in the center of pressure location (10). This lateral shift likely decreases the length of the knee joint moment arm.

These findings of our study are in concurrence Ogata et al 
(11). While studying the relationship between radiographic severity of $O A$, had also found that the amplitude of first acceleration peak decreased with the usage of valgus insoles in all 50 knees with medial $\mathrm{OA}$, and the mean reduction in first acceleration peak amplitude with the usage of insoles was $23.7 \%$.\& found pain relief so recommend the usage of insoles T Pham (12) also noted in his study on 156 patients prospective randomized controlled study to compare the clinical effects of laterally wedged insoles and neutrally wedged insoles in patients with medial femoro-tibial joint $O A$ at the end of 2 years he found that the NSAIDS requirement is lower in lateral wedge group as compare to neutral wedge insole. ( $71 \pm 173$ days VS. $127 \pm 193$ days, $P=0.003$.so they Conclude the reduced NSAIDs intake and the better compliance in the treatment group are in favor of a beneficial effect of laterally-wedged insoles in medial OA knee. laterally wedged insoles are proposed for the treatment of knee medial compartment osteoarthritis. The clinical effect is probably limited, but the treatment may reduce the digestive and renal side effects of prolonged use of non-steroidal antiinflammatory drugs.

Barrios JA, et al (13). They found while studying the clinical efficacy of individually prescribed laterally wedged orthosis and walking shoes in the treatment of medial knee osteoarthritis by using a prospective, single-blind, blockrandomized controlled design on Sixty-six subjects both groups were improved at each follow-up in the WOMAC subscales for pain, stiffness $(p<0.001)$ and physical function. Both groups also improved in 6-minute walk test distance, stair negotiation test time, and stair negotiation test pain change Van Raaij et al (14) in there study also concluded that \& suggest lateral wedge insole may be alternative for valgus brace \& conservative treatment for medial joint knee osteoarthritis.

Hameed et al (15) in there study of lateral wedge insoles on 48 knees also suggested clinically symptomatic improvement significant $p$ values on most of womac subscales \& suggest lateral wedging as conservative treatment in early medial knee osteoarthris.

\section{CONCLUSION}

From the study following conclusions could be drawn lateral wedging in shoe in a patient of medial joint $O A$ knee reduces the requirement of non-steroidal anti-inflammatory agents. Lateral wedging in shoes improves function in day to day life and improves quality of life by reducing pain. In nutshell it can be said that the lateral wedging in shoes in medial joint osteoarthritis is beneficial and it can be a good conservative treatment modalities in early osteoarthritis patients. Particularly in developing countries especially India it might a better alternative as well as the cost effective treatment modalities of osteoarthritis that can reduce the requirement of NSAIDS and improve functional level of patients by reducing pain in various activities.

\section{REFERENCES}

1. Baliunas, A., Hurwitz, D., Ryals, A., Karrar, A., Case,J., Block, J., \& Andriacchi,T. (2002). Increased knee joint loads during walking are present in subjects with knee osteoarthritis. Osteoarthritis and Cartilage, 10(7), 573-579. doi: 10.1053/joca.2002.0797

2. Sharma L, Cahue S, Song J, Hayes K, Pai YC, Dunlop DD. Physical functioning over three years in knee osteoarthritis: Role of psychosocial, local mechanical, and neuromuscular factors. Arthritis Rheum. 2003; 48(12):3359-70.

3. Jackson, B., Wluka, A., Teichtahl, A., Morris, M., \& Cicuttini, F. (2004) Reviewing knee osteoarthritis - a biomechanical perspective. Journal of Science and Medicine in Sport, 7(3), 347-357. doi: 10.1016/s14402440(04)80030-6

4. Johnson, F., Leitl, S., \& Waugh, W. (1980). The distribution of load across the knee. A comparison of static and dynamic measurements. The Journal of Bone and Joint Surgery. British Volume, 62-B(3), 346-349. doi: 10.1302/0301620x.62b3.7410467

5. Cerejo, R., Dunlop, D. D., Cahue, S., Channin, D., Song, J., \& Sharma, L. (2002). The influence of alignment on risk of knee osteoarthritis progression according to baseline stage of disease. Arthritis \& Rheumatism, 46(10), 2632-2636. doi: 10.1002/art.10530

6. Jordan, K. M. (2003). EULAR Recommendations 2003: an evidence based approach to the management of knee osteoarthritis: Report of a Task Force of the Standing Committee for International Clinical Studies Including Therapeutic Trials (ESCISIT). Annals of the Rheumatic Diseases, 62(12), 1145-1155. doi: 10.1136/ard.2003.011742

7. Recommendations for the medical management of osteoarthritis of the hip and knee: 2000 update. (2000). Arthritis \& Rheumatism, 43(9), 1905-1915. doi: 10.1002/1529-0131(200009)43:9<1905::aid-anr l>3.0.co;2-p

9. Kellgren, J. H., \& Lawrence, J. S. (1957). Radiological Assessment of OsteoArthrosis. Annals of the Rheumatic Diseases, 16(4), 494-502, doi: 10.1136/ard.16.4.494

10. Kerrigan, D., Lelas, J.L., Goggins, J., Merriman, G.J., Kaplan, R.J., \& Felson, D.T (2002). Effectiveness of a lateral-wedge insole on knee varus torque in patients with knee osteoarthritis. Archives of Physical Medicine and Rehabilitation, 83(7), 889-893. doi: 10.1053/apmr.2002.33225

11. Ogata, K., Yasunaga, M., \& Nomiyama, H. (1997). The effect of wedged insoles on the thrust of osteoarthritic knees. International Orthopaedics, 21(5), 308-312. doi: 10.1007/s002640050174

12. Pham, T., Maillefert, J.-F., Hudry, C., Kieffert, P., Bourgeois, P., Lechevalier, D., \& Dougados, M. (2004). Laterally elevated wedged insoles in the treatment of medial knee osteoarthritisllThis work was supported in part by the 'Programme Hospitalier de Recherche Clinique' (AOM 97 184) of the French Health Ministry. Osteoarthritis and Cartilage, 12(1), 46-55. doi: 10.1016/j.joca.2003.08.011

13. Barrios, J. A., Crenshaw, J. R., Royer, T. D., \& Davis, I. S. (2009). Walking shoes and laterally wedged orthoses in the clinical management of medial tibiofemoral osteoarthritis: A one-year prospective controlled trial.The Knee, 16(2), 136-142. doi:10.1016/j.knee.2008.10.002

14. Van Raaij,Raijman M,Brouwer RW, Bierma -Zeinstra SM,Verhaar JA Medial Knee osteoarthritis treated by insoles or braces : a randomized trial 2010 Jul;468(7):1926-32. doi: Arthritis Rheumatol 20192019 Jun;11(6):908-915. doi: 10.1002/art.40808. Epub 2019 Apr 8.

15. Hamed, A. E. A., Zamzam, M., El-Sebaie, M., \& Ahmed, S. (2019). The effects of lateral wedge insoles on primary knee osteoarthritis patients. Egyptian Rheumatology \& Rehabilitation, 46(3), 189. doi: 10.4103/err.err 46_18 